\title{
IRRADIATION - INDUCED CONTRACTION OF GRAPHITES AT HIGH TEMPERATURE FOLLOWING COLD PREIRRADIATION AND INTERMITTENT THERMAL ANNEALS
}

J. H. COX, E. M. WOODRUFF

JANUARY, 1966
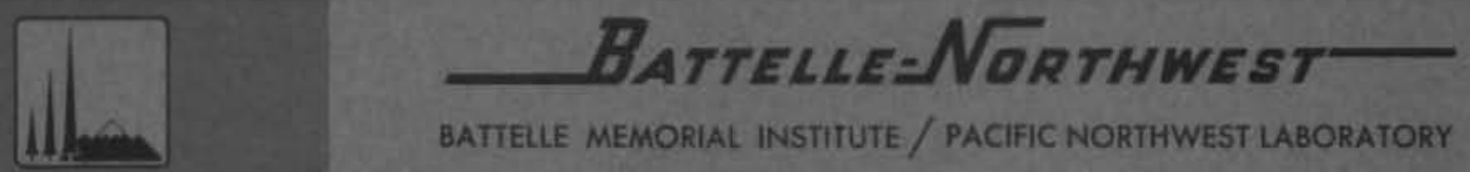

BATTELLE MEMORIAL INSTITUTE/PACIFIC NORTHWEST LABORATORY 


\section{LEGAL NOTICE}

This report was prepared as an account of Government sponsored work. Neither the United States, nor the Commission, nor any person acting on behalf of the Commission:

A. Makes any warranty or representation, expressed or implied, with respect to the accuracy, com. pleteness, or usefulness of the information contcined in this report, or that the use of any information, apparatus, method, or process disclosed in this report may not infrirge privately owned rights; or

B. Assumes any liabilities with respect to the use of, or for damages resulting from the use of any information, apparatus, method, or process disclosed in this repart.

As used in the above, "person acting on behalf of the Commission" includes any enployse or contractor of the Commission, or smployee of such contractor, to the extent that such employes or contractor of the Cammission, or employee of such contractor prepares. disseminates, or provides access to; any information pursuant to his employment or contract with the Commission, or his emplayment with such contractor:

\section{PACIFIC NORTHWEST LABORATORY}

RICHLAMD, WASHINGTON

operated by

BATTELLE MEMORIAL INSTITUTE

for the

UNITED STATES ATOMIC ENERGY COMMISSION UNDER CONTRACT AT(45-1)-1830 
BNWL- 215

UC-25, Metals, Ceramics, and Materials

\title{
I RRADIATION - INDUCED CONTRACTION \\ OF GRAPHITES AT HIGH TEMPERATURE \\ FOLLOWING COLD PREIRRADIATION \\ AND INTERMITTENT THERMAL ANNEALS
}

\author{
By \\ J. H. Cox, E. M. Woodruff \\ Ceramics and Graphite Research Section \\ Materials Department
}

$$
\text { January, } 1966
$$

PACIFIC NORTHWEST LABORATORY

RI CHLAND, WASH INGTON 
Printed in USA. Price $\$ 1.00$. Available from the Clearinghouse for Federal Scientific and Technical Information, National Bureau of Standards, U. S. Department of Commerce, Springfield, Virginia 


\section{IRRADIATION - INDUCED CONTRACTION OF GRAPHITES AT HIGH TEMPERATURE \\ FOLLOWING COLD PREIRRADIATION \\ AND INTERMITTENT THERMAL ANNELAS}

INTRODUCTION

Experimental results ${ }^{(1)}$ and discussions ${ }^{(2)}$ were recently reported where graphite samples initially irradiated at a low temperature $\left(<200^{\circ} \mathrm{C}\right)$ and then irradiated at a higher temperature $\left(300{ }^{\circ} \mathrm{C}\right)$ contract at a greater rate than samples irradiated only at tho higher temperature. This effect, caused by the seeding of radiation-produced defects at low temperature, is of interest in the design and operation of nuclear reactors as well as in fundamental graphite studies. Data are reported here on three reactor-grade graphites (KC, CSF, and TSGBF) irradiated at low temperature $\left(30^{\circ} \mathrm{C}\right)$ to $2.9 \times 10^{20} \mathrm{nvt*}(\mathrm{E}>0.18 \mathrm{MeV}$ ) then at high temperature $\left(550\right.$ to $\left.700^{\circ} \mathrm{C}\right)$ to $11.1 \times 10^{20} \mathrm{nvt}$. These data represent extreme conditions for cold seeding when compared to previous reports, ie, a longer seed irradiation at a lower temperature and a longer exposure at the higher temperatures.

Data are a1so reported on high-temperature (, $\left.500{ }^{\circ} \mathrm{C}\right)$ irradiations of reactor-grade (TSX) graphite where samples were annealed at $2500{ }^{\circ} \mathrm{C}$ after each irradiation period for comparison with control samples not annealed between exposures. Data are reported for exposures to $3.0 \times 10^{21} \mathrm{nvt}$.

PROCEDURES

Materials

The four extruded reactor-grade graphites studied were KC, CSF, TSGBF, and TSX. The properties of these materials have been

* A11 neutron exposures are given in terms of neutrons/cm ${ }^{2}$ with energies greater than $0.18 \mathrm{MeV}$. 
described elsewhere.

Processing variables of each grade are itemized below:

(1) KC - Kendall petroleum coke, Chicago coal-tar pitch, one coal-tar pitch impregnation and graphitization at 2 $2800{ }^{\circ} \mathrm{C}$,

(2) CSF - Cleves petroleum coke, Barrett medium No. 30 coaltar pitch, one coal-tar pitch impregnation, graphitization at $\sim 2800{ }^{\circ} \mathrm{C}$, and halogen purification.

(3) TSGBF - Texas petroleum coke, Barrett medium No. 30 coal-tar pitch, one coal-tar pitch impregnation, halogen purification and graphitization at $\approx 2450{ }^{\circ} \mathrm{C}$.

(4) TSX - Continental, Lake Charles, petroleum coke, Allied medium No. 30 coal-tar pitch, one coal-tar pitch impregnation, halogen purification and graphitization at $\sim 3000{ }^{\circ} \mathrm{C}$.

The anisotropy of these graphites is indicated by the ratio of transverse to parallel coefficients of thermal expansion in Table I. The KC and TSX graphites are more anisotropic than the CSF and TSGBF.

\section{TABLE I}

TYPICAL COEFFICIENT OF THERMAL EXPANSION VALUES $\mathrm{CTE} \times 10^{6}$ (25 to $\left.425^{\circ} \mathrm{C}\right)$

Graphite Type

$\mathrm{KC}$

TSX

CSF

TSGBF

$$
\begin{aligned}
& \ldots \\
& 4.7 \\
& 3.4 \\
& 3.5 \\
& 3.8
\end{aligned}
$$

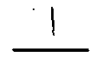

1.1

0.9

1.5

2.2
Ratio :

4.3

3.8

2.3

1.7 


\section{Specimen Preparation}

All graphites were received as bars about 4 ft in length. The KC, CSF, and TSGBF materials had 4-in. cross sections, and the TSX was 6-in. cross section. The bars were samples as shown in Figure 1. The KC, CSF, and TSGBF samples were then machined to 0.426 in. diam by 4 -in. Iong cylinders and the ends were polished. These samples were not annealed before the initial low-temperature irradiation. Stresses introduced in samples by machining, result in small (< $0.02 \%$ ) dimensional changes when annealed, and may influence low-exposure, hightemperature irradiation data. However, at the longer exposures reported here, this effect is unimportant.

The TSX samples were shaped into quarter rounds with $0.375 \mathrm{in}$. radius about $4 \mathrm{in}$. long, and the ends were polished. A11 samples were annealed at $1000{ }^{\circ} \mathrm{C}$ for $1 \mathrm{hr}$ before irradiation.

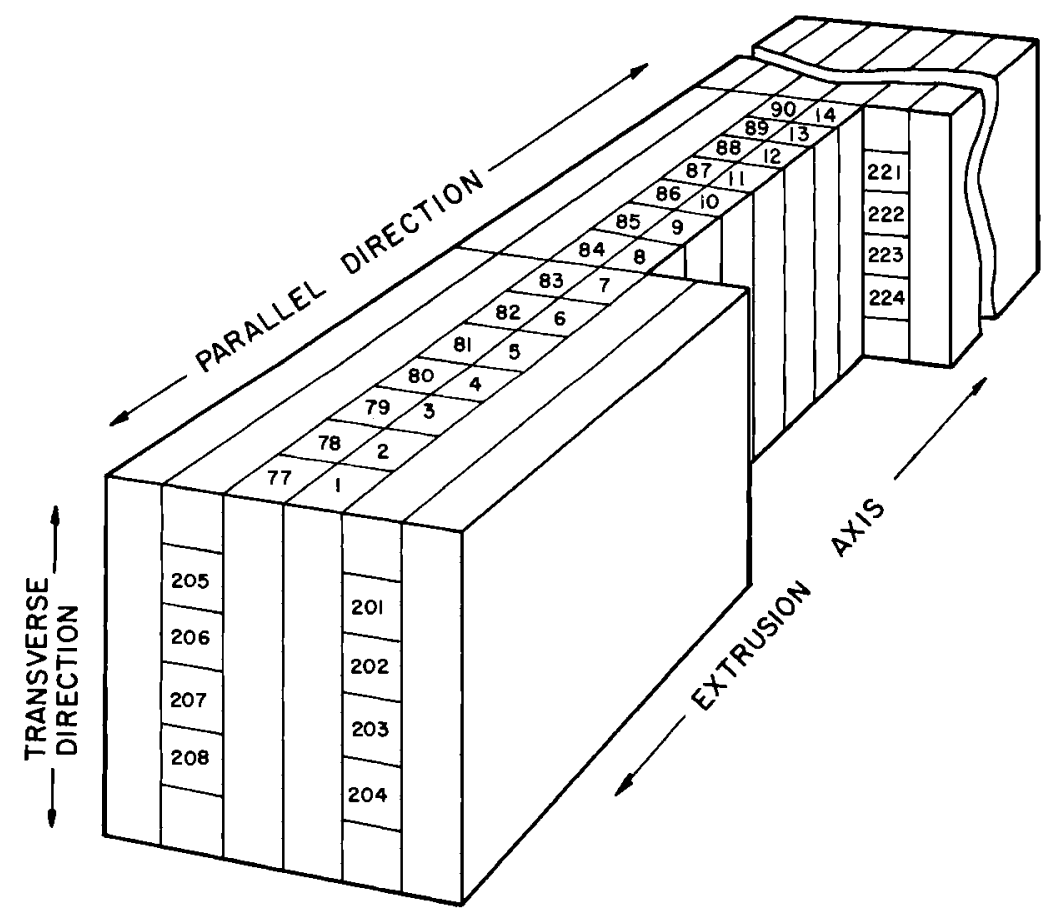

FIGURE 1

Sampling Diagram for Standard Bars 
BNWL- 215

\section{Leng th Measurements}

Length measurements were taken on each sample after each irradiation and each anneal. The length measurements for the $K C$, CSF, and TSGBF samples were taken with a micrometer to the nearest 0.0003 in. The TSX samples were measured on a Bausch and Lomb DR-25 Optical Gage (Type 33-14-23) to the nearest 0.00005 in

Irradiation conditions

Cold Irradiation - Half of the KC, CSF, and TSGBF samples were given a cold $\left(30{ }^{\circ} \mathrm{C}\right)$ irradiation prior to receiving hot (550 to $700{ }^{\circ} \mathrm{C}$ ) exposures. The cold irradiations were performed in an atmosphere of helium in water=cooled $1 / 2=i n$. aluminum tubes.

Hot Irradiation - A11 KC, CSF, and TSGBF samples were irradiated in a hot test hole in the Hanford C Reactor. During irradiation they were contained in hollow graphite bars equipped with sliding covers: Irradiation temperatures were 550 to $700{ }^{\circ} \mathrm{C}$ in a helium-carbon dioxide atmosphere. Samples having received previous cold irradiations were annealed at 700 to $750{ }^{\circ} \mathrm{C}$ for 1 hr between cold and hot irradiations.

ETR Irradiations. A11 TSX samples were irradiated in the Englneering Test Reactor (ETR) in an aluminum cylinder 21.125 in. diam $\times 5.5$ in. long; the capsule atmosphere was helium. Although the temperature varied between irradiations, the temperature for each irradiation was the same for all samples in a given capsule。 Half of the samples were annealed at $>2500^{\circ} \mathrm{C}$ after each irradiation.

EXPERIMENTAL RESULTS AND DISCUSSION Length Change

Dimensional changes for the KC,CSF, and TSGBF samples are presented in Figures 2, 3, and 4: Contraction rates and the ratio of the contraction of the seeded samples to nonseeded samples are given in Table II. 


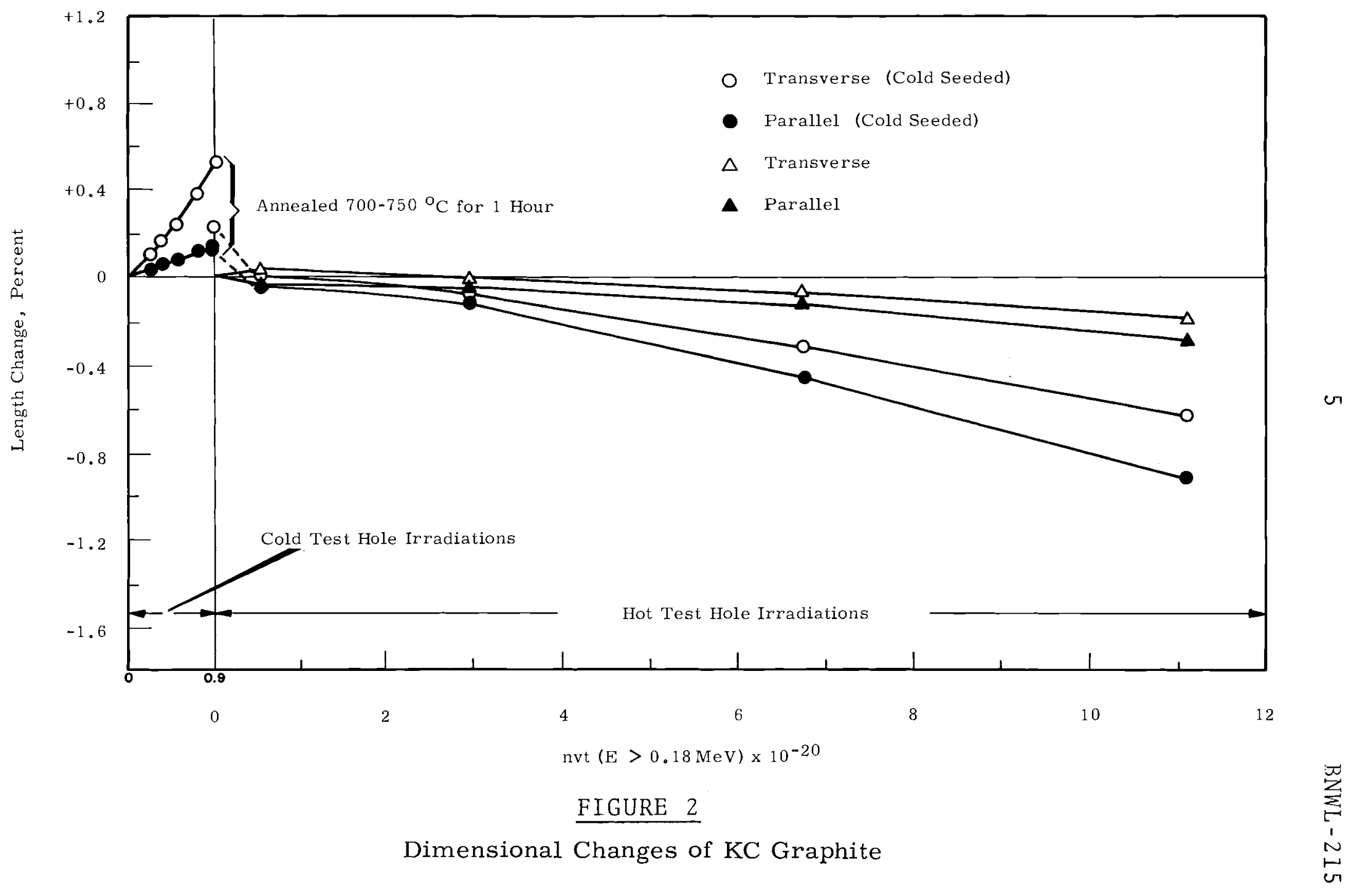




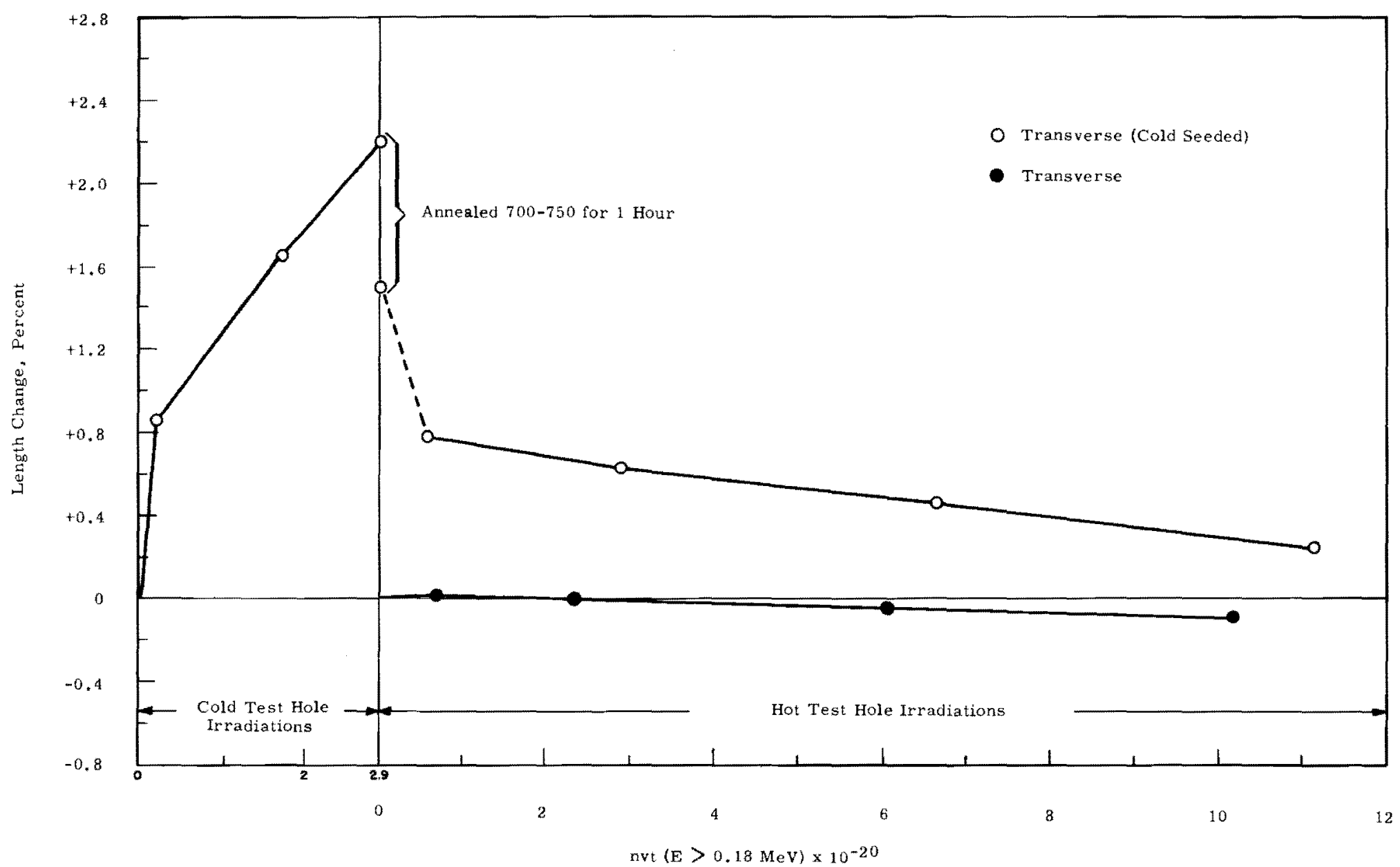

FIGURE 3

Transverse Dimensional Changes of CSF Graphite 


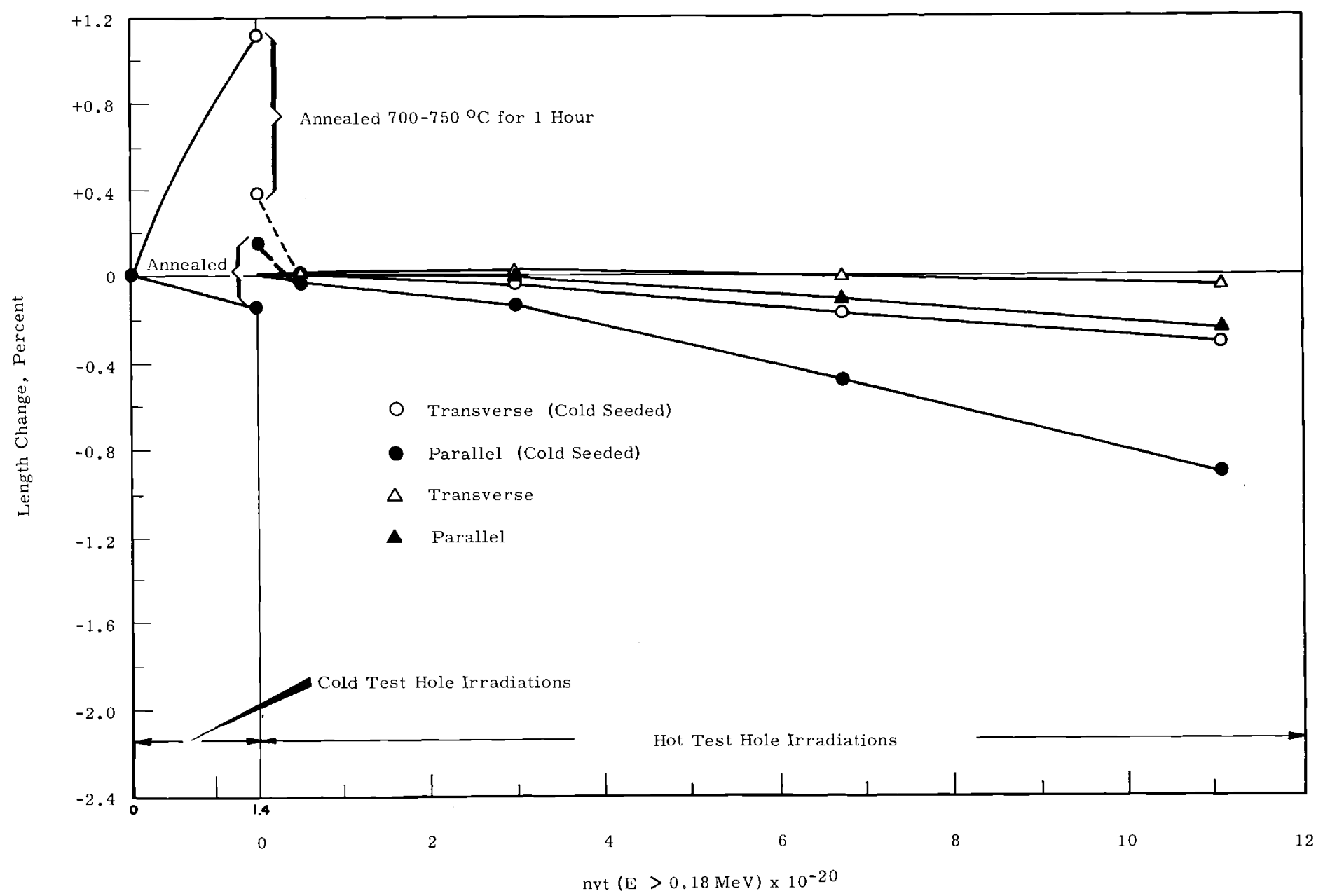

FIGURE 4

Dimensional Changes of TSGBF Graphite 
TABLE II

CONTRACTION RATES

$\left(550\right.$ to $\left.700{ }^{\circ} \mathrm{C}\right)$

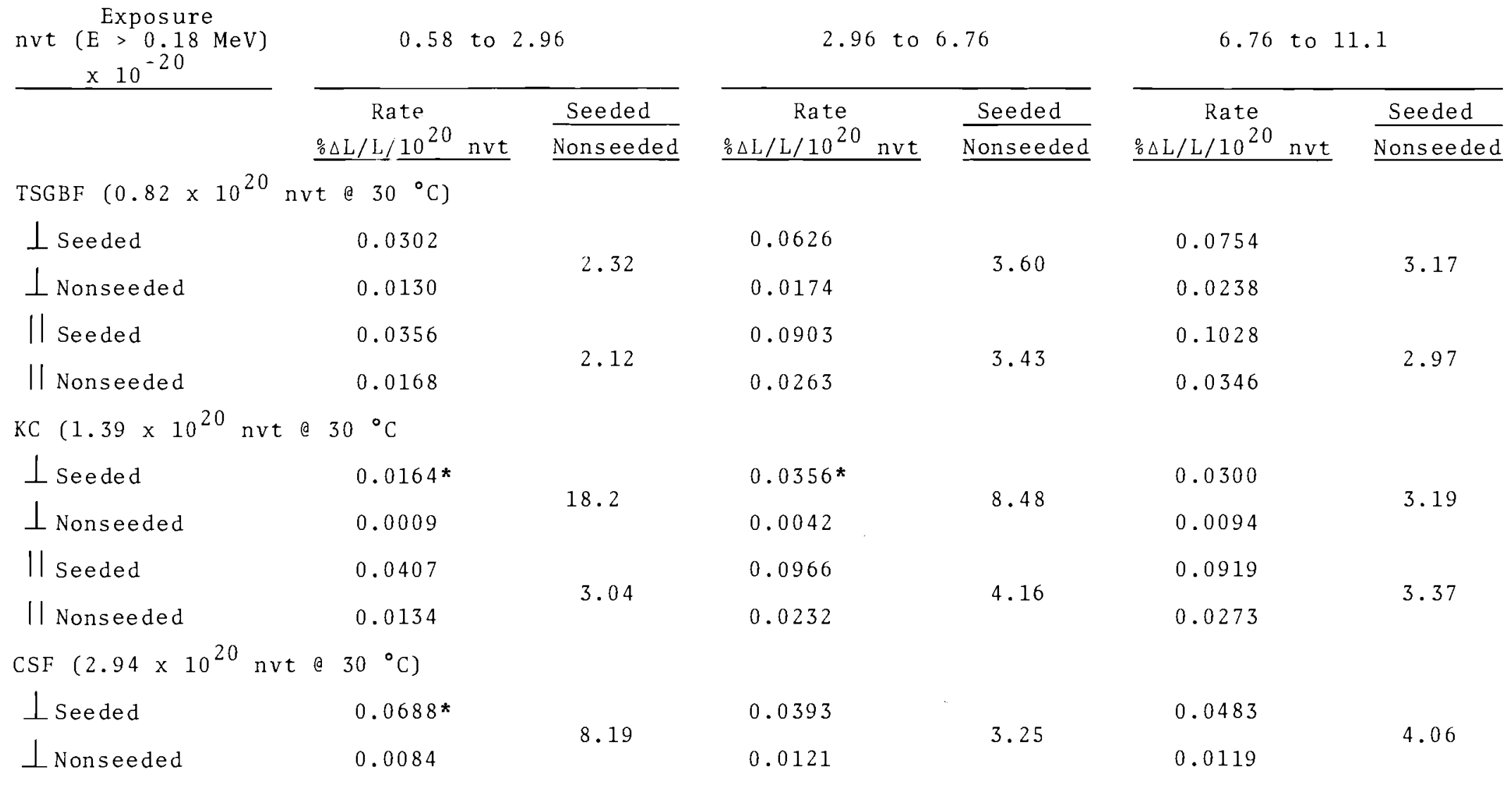

* Rates indicate the samples are not fully annealed at this exposure. 
As can be seen from Figures 2, 3, and 4, the annealing of the cold irradiation damage is in part a thermal anneal and partly an irradiation anneal. The contraction ratios in Table II indicate that in most cases the irradiation annealing is completed during the first hot exposures. However, for CSF and KC transverse samples it appears that the irradiation annealing is not completed until 2.9 and $6.8 \times 10^{20} \mathrm{nvt}$, respectively. After the annealing is completed, the ratio of the rate of contraction of the cold seeded to nonseeded samples is $3.2 \pm 1.0$ for both transverse and parallel samples of all graphite types investigated.

Since there is no significant difference in contraction ratios between the lowest and highest cold exposure, it appears that there is a limit for the cold-seed effect when applied to these irradiation temperature ranges. This investigation does not establish the minimum exposure required to reach this limit. The minimum may well vary with different graphite types and will certainly vary with different seeding temperatures. Other investigations should be conducted at higher irradiation temperatures.

Another point to be noted is that all of the graphite growth may not be annealed out at high cold exposures. An example of this is seen in Figure 3 . As a result, not only must the different contraction rate of the seeded graphite be considered, but also the amount of growth retained in the graphite.

The percentage of cold irradiation damage annealed thermally does not correlate with either length of cold exposure or degree of crystal alignment initially present in the different graphites Irradiated.

Dimensional changes of the TSX samples are presented in Figures 5, 6, and 7. The contraction rate of the samples in Capsule 1 is different than the samples of Capsule 2, Figure 7, due to different irradiation temperatures. Also, temperatures may 


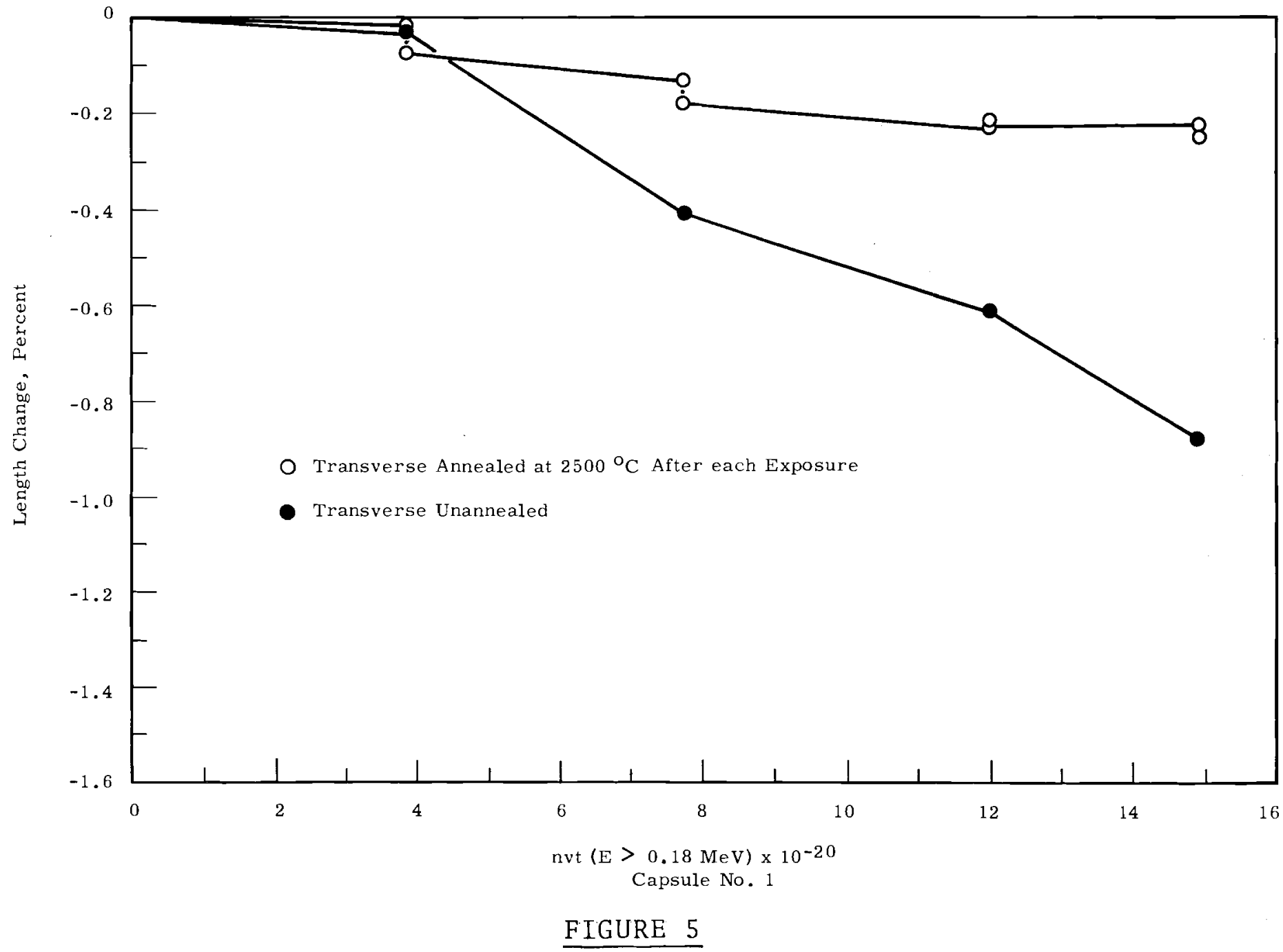

Transverse Dimensional Changes of TSX Graphite 


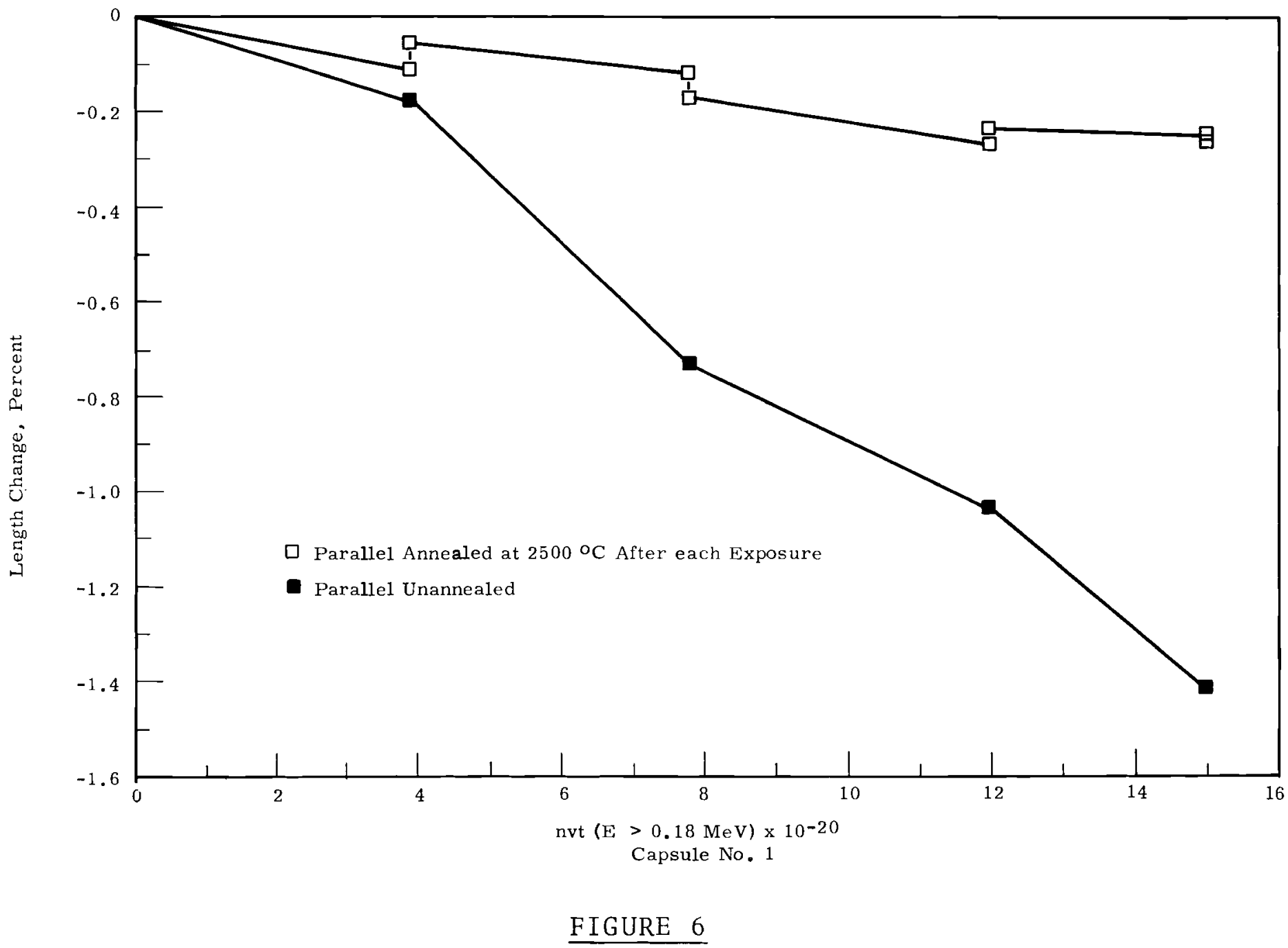

Parallel Dimensional Changes of TSX Graphite 


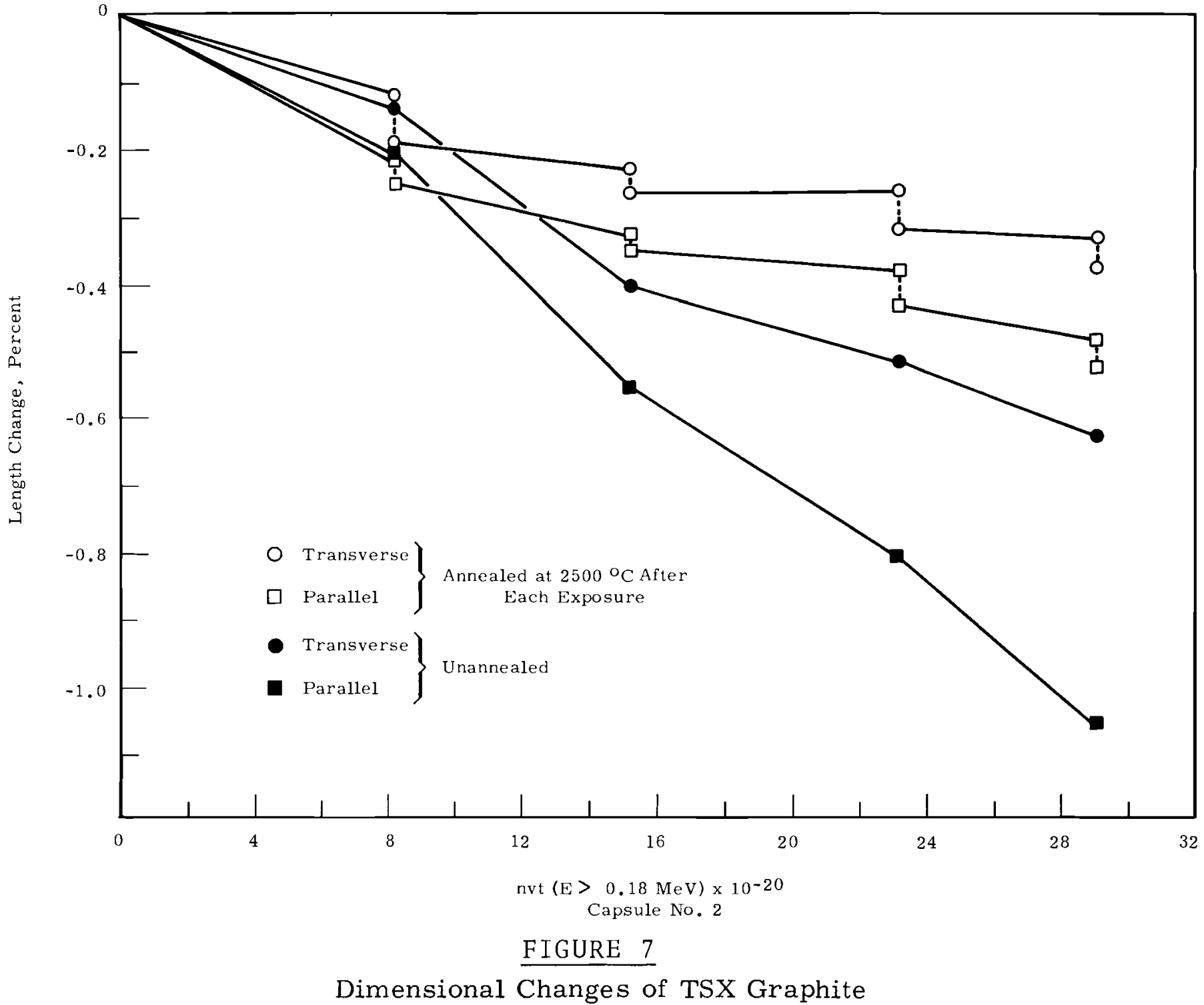


differ between irradiation periods, and as a result, the contraction rate changes considerably between exposure periods. Nevertheless, in each case the contraction is impeded by thermally annealing to $2500{ }^{\circ} \mathrm{C}$. In Capsule 1 , Figures 5 and 6 , the orientation dependence of the contraction is not evident for the annealed samples. However, the samples presented in Figure 7 do show an orientation dependence. It should be noted that the samples in Figure 7 were irradiated to about twice the exposure between annea1s. In other words, the samples in Figures 5 and 6 were annealed before they had as large an accumulation of radiation damage as the samples in Figure 7.

In an earlier report (4) of radiation damage at $30^{\circ} \mathrm{C}$, the growth rate of $\mathrm{KC}$ graphite was impeded by a $500{ }^{\circ} \mathrm{C}$ anneal after each exposure period.

These observations may a11 be consistently explained, at low exposures ( $\left.10^{22} \mathrm{nvt}\right)$, before the onset of "turnaround" $(5,6)$ and consequent growth, by assuming a dependence of contraction on the density of defects or total disorder in the graphite whether they were present initial1y or caused by neutron bombardment. The more disordered graphites, such as the cold-seeded samples which after annealing have residual damage from the first exposure, would display a more rapid contraction than the more perfect original material. In highly ordered material, irradiation even at high temperatures increases the density of defects and accelerates the contraction. However, annealing then reduces the density of defects in the graphite to a state approaching the original; therefore, the annealed well-graphitized samples contract more slowly, at rates comparable to the original material. Since the contraction rates are less orientation dependent at low exposure, there is less orientation dependence in the annealed samples in Figures 5 and 6 . However, the samples in Figure 7 were allowed to go to about twice the exposure before being annealed, and the orientation dependence is evident as would be expected at a higher damage level. 


\section{SUMMARY}

Data are presented for cold-seeding graphite. Graphites investigated are $\mathrm{KC}, \mathrm{CSF}$, and TSGBF. Cold $\left(30^{\circ} \mathrm{C}\right)$ exposures were $0.8 \times 10^{20}$ to $2.9 \times 10^{20} \mathrm{nvt}(\mathrm{E}=0.18 \mathrm{MeV})$, and hot $(550$ to $700^{\circ} \mathrm{C}$ ) exposures were to $11.1 \times 10^{20}$. The cold seeded samples were thermally annealed (to $750^{\circ} \mathrm{C}$ ) after the cold irradiation. When cold seeded all samples contracted at a greater rate; the contraction rate, independent of orientation, increased by a factor of $3.2 \pm 1.0$. Based on the wide range of both cold and hot exposures, it appears that the factor of three is a limit for the temperature ranges investigated. The minimum cold exposure required to reach this limit has not been established. Future studies should include a higher temperature range ( $800^{\circ} \mathrm{C}$ ) on the second exposure because of the trend to higher operating temperatures in graphite reactors.

This cold seeding phenomenon should be considered in reactor design and operation so the enhanced contraction may be minimized.

Samples of TSX graphite were irradiated at different tem peratures and exposures to $3.0 \times 10^{21}$ nvt; after each irradiation the samples were annealed to approximately the graphitization temperature. In each case, the contraction upon subsequent irradiation was less in the annealed samples.

\section{ACKNOWLEDGEMENTS}

The authors wish to thank several people for the data presented here. H. H. Yoshikawa with the assistance of G. E. Shook conducted the hot-capsule irradiations of TXS graphite. A. J. Jervis, Jr. assisted the authors in measuring and compiling the data for the hot-test-hole irradiations. 


\section{REFERENCES}

1. W. N. Reynolds and P. A. Thrower. "Enhanced Nucleation of Radiation Damage in Graphite," Carbon, vol. 1, pp. 185-188. 1964 .

2. G。 K. Williamson. "Seeding in Graphite," Report RD/B/N. 270 Berkeley Nuclear Laboratories, 1964.

3. Nuclear Graphite, edited by R. E. Nightingale. Academic Press, New York, 1962.

4. E. M. Woodruff. "Dimensional Changes in Irradiated Graphite," Proceedings of the US/UK Graphite Conference held at St. Giles Court, London, December 16-18, 1957, pp. 1-10.

5. J.W. Helm. The H-3 Irradiation Experiment: Irradiation of EGCR Graphite--Interim Report No. 2, HW-71500B. General Electric Company, Richland, Washington, September, 1964.

6. J. W. Helm. The H-4 and H-6 Irradiation Experiments: Irradiation of $\mathrm{N}$ - Reactor Graphite--Interim Report No. 1, HW-81250A General Electric Company, Richland, Washington, October, 1964. 


\section{ONSITE DISTRIBUTION}

\section{Copy Number}

\section{Pacific Northwest Laboratory}

1

$2 \cdot 11$

12

13

14

15

16

17

18

19

20

21

22

23

24

25

$26-35$

36

$37-41$

$42-43$

44

45

46

47

48

49

50

51
$52-53$
54
55

F. W. Albaugh

J.H. Cox

G. M. Dalen

J. M. Davidson

D. R. de Halas

J. F, Fletcher

J。 C, Fox

L. O. Gates

R. C Giberson

J. W. Helm

J. L. Jackson

L. D. Johnson

S. S. Jones

W. C. Morgan

R. E, Nightingale

L. O, Slind

E. M. Woodruff

$\mathrm{H}$. H. Yoshikawa

Technical Information Files

Technical Publications

General Electric Company, Richland

D. H. Curtiss

S. M, Graves

M. C. Leverett

$M$. Lewis

C. E. Love

A. Rus se 11

GETA Files

Richland Operations Office

L, R. Lucas

R. L. Plum

R. K. Sharp

Technical Information Library 


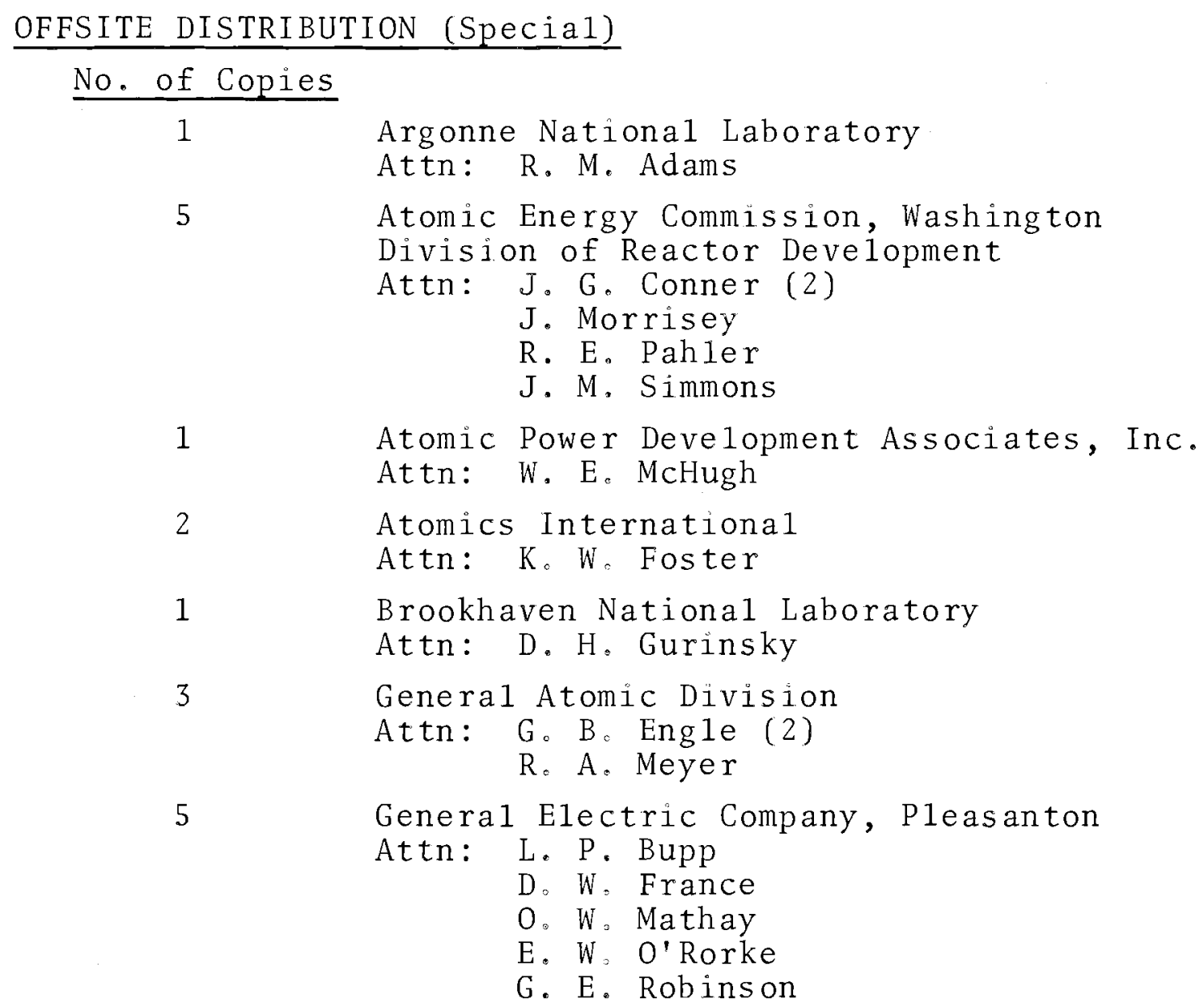

1 General Electric Research Laboratories P. O. Box 1088, Schenectady, New York Attn: E. R. Stover Great Lakes Carbon Corporation Research and Development Department P. 0. Box 637, Niagara Fal1s, New York Attn: L. H. Juel, Electrode Division Marquardt Corporation Attn: D。W. Bareis

Oak Ridge Operations Office

Attn: D. F. Cope (2)

W. J. Larkin

Speer Carbon Company

Research and Development Laboratories Packard Road \& 47 th St。, Niagara Falls, N.Y. Attn: W。E。Parker 


\section{OFFSITE DISTRIBUTION (Special)}

No. of Copies

2

Union Carbide Corporation

Attn: P. J. Hastings

L. D. Stoughton

1. Union Carbide Corporation, Cleveland Attn: J. T. Meers

8

Union Carbide Corporation (ORNL-Y-12)

Attn: B. L. Greenstreet

C. A. Preskitt

F. J. Witt (6)

Wright Air Development Division

Wright-Patterson AFB, Ohio

Attn: R. H. Wilson (Major) 